Produto \& Produção, vol.17, n.1, p.51-63,mar. 2016

RECEBIDO EM 28/04/2014. ACEITO EM 15/01/2016.

Felipe da Silva Cruz

Universidade Federal de Santa Maria - UFSM

felipe.kruz@hotmail.com

Cristiano Henrique Antonelli Da Veiga

Universidade Federal de Santa Maria - UFSM

chadaveiga@gmail.com

\title{
Estudo dos fatores que interferem no aproveitamento de chapas de aço no processo de corte
}

\section{RESUMO}

O presente estudo analisou os fatores que interferem no aproveitamento de chapas de aço oriundas do processo de corte de uma empresa de grande porte do ramo metal mecânico localizada no interior do RS. Na pesquisa foram definidos os setores e os funcionários que possuem relação direta com o aproveitamento das chapas de aço como o setor de PCP e o de estamparia da empresa. O objetivo principal foi descrever como ocorrem as ações de planejamento e de corte de chapas metálicas, mensurar o desperdício de materiais oriundo deste processo, identificar possíveis dificuldades e propor medidas que tornem o corte mais eficiente na perspectiva de perdas. Por meio de entrevistas semiestruturadas e observação direta no chão de fábrica, coletou-se os dados e após analisados são relatados neste estudo de caso. Observou-se que os principais fatores que interferem no aproveitamento das chapas de aço, para o caso em questão, foram as quantidades de peças a serem cortadas, a falta de políticas de utilização dos retalhos e as restrições impostas pelas dimensões de compras dos materiais em relação às especificadas nos projetos dos produtos.

Palavras-chave: processo de corte de chapas, desperdício, gestão da manufatura.

\begin{abstract}
The present study analyze the factors that affect the use of steel plates originated from cutting in a large metal branch company located within in the Rio Grande do Sul Estates, Brazil. In research sectors and employees who are directly or indirectly related to the use of steel plates as the sector of PCP and stamping company were contemplated. The main objective was to describe how the planning and steel cutting processes occur, measuring waste arising from the cutting process, identify potential problems and propose measures to make the process more efficient cutting. Through semi-structured direct observation in the shop floor and interviews can collect the data reported in this case study. It was observed that the main factors that affect the use of steel plates to the case in question, were the quantities of pieces to be cut, the lack of policies for the use of flaps and the restrictions imposed by the dimensions of the materials and the dimensions of product' designs.
\end{abstract}

Keywords: cutting process, waste, manufacturing management. 
Os benefícios de um sistema produtivo focado para um sistema de produção mais limpa, sem desperdícios de recursos, com gerenciamento dos riscos de acidentes do trabalho, menores custos com destinação de resíduos, diminuição do impacto ambiental e, consequentemente, com a redução de custos são questões correntes do cotidiano industrial. Embora este tema seja considerado importante, conforme Venanzi e Silva (2013), se verifica uma diversidade de pontos de vistas e de práticas empresariais voltadas para as ações desta natureza.

Este trabalho teve por objetivo identificar os fatores que interferem no aproveitamento de chapas de aço em uma empresa do ramo metal-mecânico que fabrica produtos para secagem, limpeza, armazenamento e transporte de grãos. Para a manufatura de seus produtos são processados, aproximadamente, 54.000 toneladas de aço por ano sendo que $90 \%$ desse montante estão na forma de chapas metálicas. Esse volume de material é transformado principalmente pelos processos de corte, estamparia, solda, pintura e montagem até se tornar em um produto final.

O esforço de coordenar estas questões operacionais da fábrica é das pessoas que constituem as equipes do Planejamento e Controle da Produção - PCP da empresa, cuja tarefa está centrada no cumprimento dos planos de produção e na busca de melhorias do processo de corte e no aproveitamento de chapas. Essas ações estão focadas, principalmente na análise apoiada por programas de computador para a otimização do corte das chapas metálicas. Apesar do esforço para a redução das perdas de materiais, verifica-se que do total processado, uma parte considerável de chapas metálicas não são aproveitadas e acabam tornando-se sucatas metálicas que são vendidas por um valor bem inferior ao seu preço de compra.

Diante do exposto, esse trabalho procurou identificar as causas que interferem no aproveitamento das chapas de aço do processo de corte, o qual é o principal responsável pela geração de sucatas. Este estudo buscou identificar as causas da geração de sucatas e, por meio deste levantamento, colaborar para que o processo de corte das chapas seja mais eficiente e possibilitar uma comparação do aproveitamento antes e depois. Este estudo também contribui para o estudo e análise de outros casos reais bem com oportunizar a geração de novas ações pesquisa nesta área com o intuito de aperfeiçoamento do processo industrial.

Este artigo encontra-se estruturado da seguinte forma: uma breve revisão da literatura acerca das atividades do PCP, os procedimentos metodológicos, a análise dos resultados, as considerações finais e as referências utilizadas.

\section{O Planejamento e Controle da Produção}

Ao realizar a compra, por exemplo, de uma roupa, livro, automóvel ou qualquer outro produto, muitos consumidores desconhecem o trabalho realizado pelas empresas manufatureiras para desenvolver a manufatura desses bens. Ao abordar a manufatura sob a visão baseada em recursos se observa que o reconhecimento das competências organizacionais oriundas de seus processos produtivos bem com as referidas limitações permite o desenvolvimento de estratégias e táticas de operações que lhe oportunize diferenciais competitivos frentes aos concorrentes (MAIA, 2012). O seu desdobramento em ações operacionais é alcançado por meio de processos industriais organizados devidamente gerenciados é que se torna possível esta transformação (FERNANDES, et al., 2012). Geralmente, os processos industriais são iniciados pela definição e compra dos insumos, passando pelas etapas de manufatura dos produtos e serviços, até a logística que possibilitam a entrega ao consumidor (SLACK et al., 2002).

Para que ocorra essa transformação, as organizações se utilizam de processos industriais desenvolvidos de acordo com o tipo de produto que está sendo manufaturado (RITZMAN; KRAJEWSKI, 2004). Na perspectiva da teoria da engenharia de processos e do desenho do produto, as questões de produtividade e eficiência industrial podem ser atingidas por meio de eficazes processos de gerenciamento dos processos, pela eficiência do projeto de desenvolvimento dos produtos e pela sua sistemática seleção de métodos de melhoria do gerenciamento das operações 
interligadas com a melhoria do desenho do produto com vistas ao aumento da eficiência da manufatura e do produto final (HINCKELDEYN; DEKKERS; KREUTZFELDT, 2015).

No que tange ao gerenciamento de um típico processo industrial, esse é liderado pela equipe de Planejamento e Controle da Produção - PCP (TUBINO, 2008), que pode ser definido como "uma função de apoio de coordenação das várias atividades de acordo com os planos de produção, de modo que os programas preestabelecidos possam ser atendidos com economia e eficiência" (RUSSOMANO, 1995 , p. 49). O grupo de pessoas que atuam no PCP também são as responsáveis pelo desenvolvimento e disseminação dos conceitos e sistemáticas de gerenciamento fabril buscando a melhoria do desempenho da organização que se utilizam dessa sistemática de organização da manufatura (LOULY; DOLGUI, 2011). Observa-se ainda que a equipe do PCP necessite dar apoio e coordenação às diversas atividades fim de uma fábrica, bem como se envolver na solução de quase todos os problemas ocorridos na produção. É um setor que interliga as questões da fabricação com as de compras e as necessidades dos clientes.

A necessidade de planejamento da produção deriva da inércia intrínseca dos processos decisórios que incluem recursos físicos, e pode ser entendida como o tempo que decorre da tomada de decisão até que ela surta efeito (CORRÊA; CORRÊA, 2006). Assim, a preocupação do PCP está centrada na eficiência da fábrica. A utilização de programas computacionais possibilita o gerenciamento de informações e dos fluxos dos processos reais da manufatura, cabendo ao PCP buscar um estado de equilíbrio para dar condições de eficiência à indústria como um todo (ISHII, 2011), bem como na utilização e implantação de técnicas para a melhoria do uso dos recursos de manufatura utilizados pela empresa (RODRIGUES; COSTA; DO CARMO, 2013).

Uma das principais ações no chão de fábrica realizadas pelo PCP destacam-se a programação, emissão e gerenciamento das ordens de fabricação cuja finalidade é viabilizar as sequências de produção dos itens dentro da fábrica. Significa dizer que sua função de preestabelecer a ocasião em que serão executadas as operações da fabricação pelas quais passarão os componentes (RUSSOMANO, 1995). Assim, para que um sistema de parametrização que utilize o MRP como base de cálculo para a programação das quantidades de materiais de uma fábrica é necessário o registro dos fatores que constituem a árvore do produto, o tamanho do lote de fabricação, o tempo de atendimento dos materiais e o estoque de segurança (BOYER; VERMA, 2010).

As informações referentes ao que foi fabricado são geradas a partir da movimentação das respectivas ordens de fabricação, dos controles e seus respectivos registros. $\mathrm{O}$ acompanhamento da produção é a função que permite a introdução de correções que garantirão a execução do programa de produção previsto (TUBINO, 2008).

Nesta perspectiva, pode-se dizer que os processos produtivos são oriundos das relações existentes no âmbito empresarial, desde questões técnicas, gerenciais, computacionais até as relações pessoais existentes entre os membros das mais variadas equipes de uma organização. Neste sentido, "a relação humana no contexto do processo produtivo depende do que os humanos oferecem (como inputs) para esta relação e, ainda, de como tal relacionamento é sentido pelos atores da interação (como outputs)" (FRÖNER, 2013, p. 82). Assim, é na qualidade do processo de relações humanas que as equipes de PCP propiciam o desenvolvimento dos processos empresariais.

No contexto do chão de fábrica, as pessoas que laboram no PCP são os agentes dessas interações, bem como pela condução da execução das ações da manufatura. Ao analisar a produção sob essa perspectiva verifica-se a importância do papel do profissional que atua no campo da produção para que o desempenho operacional seja atingido de acordo com os objetivos previamente estabelecidos. Nesta perspectiva, verifica-se que as atividades do PCP apresentam algumas características em comum nas mais variadas organizações empresariais, não existindo um sistema universal que o caracterize como um padrão a ser seguido (DUTRA; ERDMANN, 2007). A diversidade e a complexidade dos sistemas produtivos inerentes à cada empresa e a maneira como são organizados os seus processos e os estilos de gestão é que oportunizam uma caracterização da estruturação e das atividades desenvolvidas pelo Planejamento e Controle da Produção.

\section{Caracterização da Pesquisa}

O objetivo deste trabalho foi identificar os fatores que interferem no aproveitamento de chapas de aço em uma empresa brasileira do ramo metal mecânico, fabricante de equipamentos para 
armazenagem, beneficiamento e movimentação de granéis, incluindo produtos como silos metálicos, transportadores horizontais e verticais, secadores e máquinas de limpeza de grãos.

A trajetória da pesquisa foi norteada pelo método de estudo de caso único cujas orientações propostas por Yin (2006) se justificam devido às características singulares da organização em questão. A empresa analisada é a maior fabricante de silos agrícolas da América do Sul sendo responsável de 90\% das exportações brasileiras de produtos para armazenagem, beneficiamento e movimentação de granéis. Sua capacidade total de produção é de aproximadamente 100 mil toneladas de aço por ano.

A pesquisa foi realizada no período de março a maio de 2012 delimitada nas etapas e máquinas em que ocorrem a maior geração de sucata e retalhos, ou seja, nos setores de corte e de estampagem, principalmente em guilhotinas, oxiplasmas, centros de corte laser e puncionadeiras, onde foram entrevistados os funcionários que possuem atuação direta com o aproveitamento das chapas de aço com espessuras que variam de $0,80 \mathrm{~mm}$ a $50,8 \mathrm{~mm}$.

O método utilizado neste estudo foi o da pesquisa descritiva que, segundo Hair Jr. (2005, p.86) é estruturada de maneira a identificar as principais características de um determinado cenário e a realização das suas descrições com o intuito de se responder uma questão de pesquisa. De acordo com Gil (2007, p.42) "as pesquisas descritivas têm como objetivo primordial a descrição das características de determinada população ou fenômeno ou, então, o estabelecimento de relações entre variáveis".

A coleta dos dados foi realizada diretamente no processo fabril, sendo considerada como fonte primária e, a partir destes, foram elaboradas planilhas e relatórios que oportunizaram a geração de informação sobre os desperdícios de materiais. De acordo com Martins (2006), para refinar a análise dos dados realizaram-se entrevistas semiestruturadas com os programadores de produção, operadores de máquinas, equipe do PCP e da engenharia do produto para verificar as visões de cada setor e como esses podem estar colaborando para melhorias nos resultados do índice de sucata. Também foram obtidos dados históricos de anos anteriores considerados como de fonte secundária. Os dados secundários se referem ao ano de 2011 e coletados junto ao setor de Programa CNC.

Também foram realizadas observações do tipo visual, no depósito de sucatas, para se compreender os principais problemas e o estado de conformidade das sucatas encontradas. Esse procedimento, de acordo com Marconi e Lakatos (2007), pode ser definido como observação direta intensiva.

A abordagem qualitativa na pesquisa de engenharia de produção, de acordo com Cauchick (2012), oportuniza ao pesquisador investigar uma organização, identificar lacunas, fazendo observações e, sempre que possível, coletar evidências para responder aos seus objetivos. Fornece, ainda, maior flexibilidade para adequação da estrutura teórica ao estudo do fenômeno administrativo e organizacional.

Ao término da pesquisa os dados quantitativos foram tabulados e analisados pelo cruzamento de informações realizadas com o uso de planilha eletrônica (HAIR et al., 2005) e juntamente com os qualitativos foram definidas categorias emergentes, por meio da Análise Textual Discursiva (Moraes; Galiazzi, 2007), consideradas relevantes que auxiliaram no diagnóstico dos problemas e na elaboração de proposições de melhorias.

Para apresentar os resultados do estudo, estruturou-se o mesmo em três partes: a primeira centrou-se na análise dos desperdícios ocorrido durante os processos; a segunda está relacionada as dificuldades que o setor de programação da produção encontra para realizar o aproveitamento das chapas e, finalizando a análise dos dados, são apresentadas sugestões de melhorias.

\section{Análise e Resultados}

Apesar do esforço atual na utilização racional das chapas de aço por parte das equipes de PCP e operacional, uma parte desse material acaba não sendo utilizada para a fabricação das peças e se transforma, em alguns casos, em chapas para retalho de produção e uma parte considerável torna-se sucata metálica.

São consideradas chapas para retalhos de produção, na empresa em questão, as sobras das chapas metálicas resultantes do processo de corte que podem ainda ser transformadas em peças, bastando, para isso, que se faça um lote (programação) utilizando essas sobras. 
Os retalhos provenientes do corte são armazenados em prateleiras ou pallets e permanecem neste local a espera de destinação por parte dos programadores CNC. Devido a alta variabilidade de tamanhos, da falta de informações gerenciáveis via sistema sobre os retalhos existentes na fábrica, das restrições das máquinas operatrizes, de questões de segurança no trabalho e principalmente falta de identificação correta do tipo de material armazenado, nem sempre os retalhos de chapa conseguem ser utilizados pelos programadores CNC tornando-se, mesmo assim, em sucata metálica, as quais são consideradas as sobras de chapas que não se consegue mais produzir peças. A sucata é vendida para outras empresas como as fabricantes de arruelas ou para os próprios fornecedores.

\subsection{Desperdício durante o processo}

Para quantificar os níveis de aproveitamento dos lotes de cada máquina, em relação aos diferentes tipos de chapas de aço, primeiramente as chapas metálicas foram separadas por espessura e registrados o peso total existente, o das peças fabricadas a partir destas e da perda resultante do processo de corte. O levantamento de dados foi realizado para possibilitar a organização dos dados em grupos de máquina como as Guilhotinas, Laser, Puncionadeiras e Oxiplasma. Os dados oriundos de cada máquina, foram somados as outras de seu grupo originando um percentual de aproveitamento geral.

Observou-se que a Guilhotina é o tipo de máquina que possui o melhor aproveitamento dentre as pesquisadas. Isso se deve as peças cortadas nessa máquina possuírem formato retangular, o que facilita o aproveitamento das chapas, também ao fato da máquina não possuir garras para fixação e movimentação e trabalhar com margens menores de segurança para os operadores (embora existam os dispositivos de segurança necessários instalados).

Ao analisar os dados referentes ao aproveitamento das duas máquinas Puncionadeiras, os valores referentes ao peso das chapas, peças e da perda cujo aproveitamento geral, em 2011, ficou em $87,59 \%$ oriunda pelo fato destas máquinas trabalharem com garras mecânicas de fixação para chapas o que exige margens de segurança maiores do que as das guilhotinas, ocasionando a redução rendimento de aproveitamento de chapas.

No que concerne as máquinas Laser utilizadas pela empresa, os valores referentes ao aproveitamento anual, em 2011, ficaram em 80,58\%. Os números desse tipo de máquina sofrem influência principalmente das restrições impostas pelos blanques e pelo formato de suas peças. Geralmente é nessa máquina onde são feitas as peças mais complexas, com curvas, redondas ou com formas desuniformes, o que dificulta o aproveitamento das chapas durante o corte.

A Oxiplasma é a máquina onde fica mais clara a influência dos blanques no aproveitamento das chapas de aço, pois ela trabalha quase exclusivamente com chapas compradas em medidas prédeterminadas pelos fabricantes.

O aproveitamento geral do processo de corte da empresa, no ano de 2011, fechou em 87,27\% do peso total manufaturado. Durante o ano foram processadas $20.593,85$ toneladas de material, de onde foram originados 17.972,38 toneladas de peças, resultando ainda em uma perda de 2.621,46 toneladas de aço, na forma de sucata metálica ou retalhos.

A empresa não autorizou a divulgação de valores referentes a compra e venda de seus materiais, porém para dar uma melhor noção dos custos envolvidos, foi pesquisado um preço médio de compra do aço e um preço médio de venda da sucata. Esses valores não são os reais utilizados pela empresa, mas na média de mercado, e visam apenas ilustrar o caso. Ao se considerar o preço de compra como sendo de $\mathrm{R} \$ 2,00$ e o de venda como sucata de $\mathrm{R} \$ 0,30$ o quilograma, teríamos um custo de $\mathrm{R} \$ 4.456 .496,05$ no ano de 2011 referente a sucata proveniente das atividades de corte da empresa. Acrescenta-se a este custo a perda econômica provocada pelo valor adicionado ao quilo processado pela empresa, ou seja, aquele representado pela quantidade monetária que a empresa ganharia com aquela quantidade de aço se a mesma tivesse sido utilizada para fazer uma peça.

$\mathrm{Na}$ busca de maiores detalhes acerca do índice de sucata de chapas metálicas foram realizadas entrevistas com os programadores, com vistas a identificar as maiores dificuldades encontradas que, segundo esses profissionais, acabam por dificultar um melhor aproveitamento. O detalhamento destas dificuldades é descrito no tópico a seguir. 
4.2 Dificuldades encontradas pela equipe do setor de Programação CNC para o aproveitamento de chapas metálicas

Evitar o aparecimento de retalhos e sucata é uma das atribuições do setor de programação CNC. Dentre os fatores que interferem no aproveitamento das chapas de aço citados pelos programadores CNC destacam-se: as dimensões das peças dos produtos serem inadequadas ao aproveitamento de chapas; pedidos urgentes de produção fora da programação fechada; poucas ordens de fabricação; falta de padronização do material; largura do material disponível; falta de peças pequenas; caraterísticas das máquinas (bordas e garras); estoque de peças pequenas; qualidade do material; blanques de chapa fina; questões de segurança; má identificação dos retalhos; falta de informação sobre os retalhos no sistema e pouco tempo disponível para criação dos lotes.

Ao considerar a primeira dificuldade apontada pelos programadores $\mathrm{CNC}$, ou seja, as dimensões das peças dos produtos serem inadequadas ao aproveitamento de chapas, foi investigado, por meio da análise dos mapas de corte, que alguns desenhos de produto realmente dificultam uma melhor utilização dos materiais. Como exemplo, existem peças com dimensões de $1800 \mathrm{~mm}$ x $501 \mathrm{~mm}$, e o equipamento de desbobinar o material disponível é para bobinas metálicas de $1000 \mathrm{~mm}$ de largura. Nesse caso, não se consegue cortar duas peças uma ao lado da outra, porque totalizariam $1002 \mathrm{~mm}$ o que ultrapassariam a largura da bobina e as especificações do produto. Ao se investigar a utilização da peça com uma nova dimensão de $500 \mathrm{~mm}$ de largura, esta redução de $1 \mathrm{~mm}$ não representaria mudança significativa ao produto final, mas se melhoraria significativamente o aproveitamento das chapas pois duas peças totalizariam $1000 \mathrm{~mm}$ de largura e a chapa desbobinada seria quase totalmente aproveitada. Nesse caso, o projeto oriundo da engenharia do produto é que acaba por afetar o aproveitamento do material na fábrica.

Outro fator relatado trata da imissão de ordens de fabricação urgentes. Essas ordens têm que ser programadas em separado das demais para acelerar a sua fabricação dentro da fábrica, sendo geralmente utilizados blanques de chapas para esses casos, para que se evite perder tempo desbobinando chapas na máquina denominada de desbobinador. Porém devido a esta ação, frequentemente, apenas uma pequena parte do blanque é usada, e o resto fica na fábrica como retalho. As ordens de fabricação urgentes possuem diversas origens: podem ser peças que não foram projetadas pela engenharia do produto, peças de reposição, pedidos em atraso, pedidos vendidos com prazo curto de entrega, peças oxidadas no estoque, entre outros motivos.

Outra questão que afeta o aproveitamento da matéria-prima é o número de emissão de ordens de fabricação. Quanto maior o número de ordens maior a quantidade de peças para serem trabalhadas pelo programador, assim ele pode otimizar o aproveitamento da chapa ao usar as peças menores nas partes ociosas oriundas das grandes peças. Na visão dos programadores isso é um dos motivos mais nítidos que impactam no aproveitamento, e pode ser visto nos meses de baixa na empresa, caracterizado pelo primeiro trimestre do ano. No entanto, ao realizar a relação quantitativa do nível de aproveitamento x o número de ordens emitidas não foi possível se obteve confirmação da informação passada pelos programadores CNC. Constatou-se que meses com emissão de quantidades de ordens de fabricação similares tem níveis de aproveitamento distintos. Porém descobriu-se, durante a pesquisa, que o fator determinante no aspecto quantidade não era o número de ordens de fabricação e sim a quantidade de peças. Uma grande quantidade de ordens nem sempre é garantia de uma grande quantidade de peças, pois quando o MRP gera as ordens, ele calcula as necessidades e as agrupa. Por exemplo, havendo necessidade de uma porta de silo, o MRP irá gerar uma ordem para a fabricação de uma unidade de porta de silo, mas havendo necessidade de três portas, ele ira gerar uma ordem para as três unidades da peça. Neste caso, o que afeta realmente para o aproveitamento das chapas é o número de peças que é necessário para ser produzido.

Nos meses com os melhores índices de aproveitamento são também os que possuem a maior quantidade de peças, sendo o mês de dezembro é uma exceção. Nele, o peso das peças é menor e o aproveitamento também é bom, as ordens de dezembro possuem uma quantidade grande de peças, assim como nos meses anteriores, o seu peso só é menor porque o tempo trabalhado é menor. Um dos motivos é que em dezembro, na empresa, há uma parada para os feriados, sendo que durante esta parada não são geradas ordens de produção. 
A falta de padronização do material também acarreta problemas para os programadores CNC, existem muitos tipos de chapas de mesma espessura e características parecidas, o que faz com eles tenham de programar mais lotes e com quantidades de peças menores. Um exemplo disso é o material denominado de BLUE, que é um tipo de aço com as mesmas características do aço ZAR, apenas de fornecedores diferentes, porém há especificações de peças para cada um dos dois tipos de materiais, o que faz com que se tenha que fazer lotes separados para materiais com mesma propriedade.

Em outro caso, a largura das bobinas ou dimensões dos blanques encontrados a venda no mercado não favorecem um bom aproveitamento, o que acaba limitando o trabalho dos programadores CNC. Existem alguns tipos de chapas que são utilizados para fabricar apenas um tipo de peça pela empresa, mas nem sempre os blanques e as bobinas disponíveis no mercado têm medidas próximas as das peças a serem manufaturadas. A empresa acaba comprando o material já sabendo que irá gerar sucata.

A falta de peças pequenas também é um dos motivos que, segundo os programadores CNC, impede a utilização total das chapas. Quando existe uma quantidade significativa de peças grandes para serem cortadas, sobram pedaços de chapas, que geralmente são utilizados para fabricação de peças com dimensões menores. Porém existem alguns tipos de chapas que são utilizadas apenas para fabricar peças grandes, o que acaba gerando retalhos que nem sempre se consegue utilizar posteriormente. Também se deve observar que por mais que existam peças pequenas para serem cortadas junto com as grandes é necessário que haja necessidade de ambas para algum cliente, pois só assim o MRP irá gerar ordens de fabricação. Como nem sempre os produtos vendidos incluem peças de todos os tamanhos, o fator mercado, neste caso, também influencia no aproveitamento das chapas.

Uma das táticas operacionais ainda utilizada pela empresa para acelerar o processo, e garantir o cumprimento dos prazos, é fabricar estoques das peças tipicamente com maior saída. Esses estoques são feitos analisando-se o histórico de vendas e os pedidos em carteira. Essa medida também é utilizada nos períodos de baixa produção como estratégia para manter a fábrica com um bom volume de produção e manter as máquinas funcionando. Porém isso acarreta uma espécie de efeito colateral, geralmente os itens de maior saída, também são os itens de menor tamanho, que são utilizados pelos programadores para melhorar o rendimento dos lotes, quando se faz estoques desses itens, o MRP não enxerga necessidade de fabricação e não gera ordens para eles, com isso, os programadores acabam tendo de programar as peças maiores com o auxílio de poucas peças menores.

A qualidade do material acaba afetando também o seu próprio aproveitamento, isso é mais evidente em máquinas LASER e OXIPLASMA. Ao programar os lotes dessas máquinas o programador pode aproximar bastante as peças umas das outras para obter o máximo de aproveitamento, mas para isso é necessário que as chapas estejam perfeitamente planas. Quando isso não acontece o laser ou plasma pode perfurar peças já cortadas que estejam ao lado da que esta sendo cortada no momento. Ao perceber que as chapas que estão no estoque não se apresentam planas o programador deixa uma distância maior entre peças como segurança, para garantir a integridade das peças, e consequentemente isso aumenta a perda de material.

As bobinas são rolos de chapas que podem ser desenroladas e cortadas com o auxílio de uma desbobinadeira. Quando o operador da máquina termina de desbobinar os blanques, ele prende o restante da bobina com cintas metálicas para que ela não se desenrole e a devolve para o estoque. Algumas vezes ao terminar de desbobinar e blanquear as chapas, há sobra de apenas uma pequena quantidade de chapas na bobina, quantidade essa que impede que a mesma possa ser enrolada novamente e presa pelas cintas metálicas da desbobinadeira. Quando isso ocorre o operador da máquina faz blanques de $3000 \mathrm{~mm}$ de comprimento com o restante da bobina, após isso ele as devolve para o estoque para serem manufaturados futuramente para fabricação das peças. Porém a utilização destes blanques estocados para fazer os lotes geralmente acarreta um pior aproveitamento do material, pelo fato dos programadores ficarem limitados as dimensões das chapas previamente cortadas, o que não acontece quando se utiliza o corte de bobinas, onde se pode definir o comprimento que se deseja. Por exemplo, uma peça de $2.600 \mathrm{~mm}$ x $900 \mathrm{~mm}$ de comprimento ao ser programada com chapas de estoque, de $3.000 \mathrm{~mm} \times 1.000 \mathrm{~m}$ daria uma perda maior do que se fossem desbobinadas chapas de $2.620 \mathrm{~mm} \times 1.000 \mathrm{~mm}$ pela desbobinadeira, a partir de uma bobina.

As questões relativas à segurança do trabalho também acabam por afetar o aproveitamento das chapas de aço, isso fica mais evidente nos lotes de guilhotina onde o operador de máquina tem mais contato com as chapas e suas mãos ficam próximas a navalha de corte. Ao fazer os lotes o 
programador CNC deve observar e prever distâncias seguras aos operadores. Quando há peças estreitas, geralmente não se consegue utilizar toda a chapa, pois a medida que o operador vai empurrando a chapa contra a navalha para cortar as peças, vai também aproximando as mãos dela. Isso faz com que em lotes de guilhotina com peças muito estreitas, o programador CNC tenha que considerar uma margem de chapa de segurança, para se evitar acidentes do trabalho. Neste caso, é norma garantir a integridade física dos colaboradores em detrimento do aproveitamento de chapas.

Outro dos problemas citados é a falta de identificação correta dos retalhos, o que impossibilita a sua utilização. Para programar uma peça, a partir de um retalho, é necessário que se saiba que tipo de chapa é, bem como a sua espessura. O que se verificou, ao percorrer o depósito da empresa que alguns grupos de chapas armazenados como são identificados corretamente ou várias chapas de diferentes tamanhos misturadas em um mesmo local, o que impede o seu uso por parte da programação CNC. Por exemplo, em um depósito para chapas com espessura $3 \mathrm{~mm}$ existiam mais de 10 tipos diferentes de chapas, que visualmente são muito parecidas, mas que depois de misturadas não há como identificar qual é qual.

Outro problema encontrado é a falta de informações sobre as dimensões reais dos retalhos que estão na fábrica. Para conseguir utilizar esses retalhos o programador $\mathrm{CNC}$ tem de se dirigir constantemente até a fábrica para verificar os retalhos disponíveis e suas medidas. Um dos problemas encontrados é quando os retalhos maiores são empilhados sem o auxílio de pallets, nesses casos mesmo que os retalhos estejam bem identificados é impossível realizar a conferência das dimensões, devido as chapas que estão armazenadas na parte superior do empilhamento impossibilitarem a tomada de informações das chapas que estão na parte inferior do estoque.

Os retalhos pequenos, aqueles que têm dimensões de até $1.000 \mathrm{~mm} \times 1.000 \mathrm{~mm}$, são armazenados em duas prateleiras que se encontram no setor de corte. Essas prateleiras contam com divisórias para separação e etiquetas de identificação da espessura e de tipo de material. Desta forma, se torna dispensável a identificação de cada retalho individualmente, apenas se deve colocá-lo na divisória correspondente. Contudo há etiquetas que apresentam apenas a espessura das sobras e não o tipo de material, tornando a identificação falha. $\mathrm{O}$ uso de um material inadequado, como de qualidade inferior ao especificado pode acarretar problemas estruturais sérios nos produtos e a correta identificação da chapa é o que possibilita o seu uso por parte da programação CNC.

Outro problema refere-se a quantidade e capacidade inadequada de prateleiras para armazenamento dos retalhos. Neste momento, existem apenas duas prateleiras, cada uma com 10 repartições, sendo que são adotados mais de 100 tipos diferentes de chapas. Assim, os espaços de algumas prateleiras são preenchidos em sua totalidade com rápida velocidade. Isto obriga os funcionários a deixarem os novos retalhos sobre pallets, no chão, na parte externa da fábrica ou sobre carros de transporte dificultando a sua busca para posterior reutilização.

Por fim, o fator tempo também acaba afetando o trabalho dos programadores CNC, geralmente cada programador tem de programar cerca de 1.100 ordens de fabricação por semana, o que geralmente faz com que ele evite dedicar tempo para solucionar problemas de pequenas perdas nos lotes, e isso se torna uma perda "aceitável", principalmente quando há ocorrência concomitante de elevados volume da produção, ordens urgentes, máquinas paradas, entre outros fatos.

Diante do exposto, foram elaboradas propostas de melhorias para a gestão das operações da organização em estudo, sendo estas debatidas no tópico a seguir relatado.

\subsection{Cenário proposto}

Após a realização do estudo pode-se identificar algumas dificuldades enfrentadas pelos envolvidos com o processo de corte. Essas dificuldades podem ser consideradas também oportunidades de melhoria por meio do aperfeiçoamento de seus processos, conforme ilustrado sinteticamente no Quadro 1. Esta seção tem como objetivo propor medidas que tornem o processo de corte mais eficiente na utilização das chapas de aço.

Um dos fatores citados como prejudiciais, são as dimensões das peças, que ás vezes, não favorecem um melhor aproveitamento, porém, não se pode exigir que o setor de engenharia projete as peças dos produtos pensando no aproveitamento da matéria-prima, cada peça é cuidadosamente projetada com uma finalidade específica, e suas dimensões atendem o seu propósito. O que se pode 
fazer é criar algum mecanismo, um guia, uma cartilha, que mostre aos engenheiros do produto quais são as melhores dimensões para cada tipo de chapa, para que, quando for possível, aproximar as peças dessas medidas para que se evite que se tenham peças com $501 \mathrm{~mm}$ de largura sendo que os materiais são processados com largura máxima de $1000 \mathrm{~mm}$. Também após a identificação de eventuais peças problema elas possam ser revisadas e até redesenhadas. A programação CNC também poderia comunicar a engenharia quando esse fato ocorresse, servindo como apoio.

Um exemplo poderia ser em relação às peças cujas dimensões de medidas são de $334 \mathrm{~mm}$ de largura por $3069 \mathrm{~mm}$ de comprimento e feitas a partir de chapas 1,25 NBR, material que só é encontrado a venda nas larguras de $1000 \mathrm{~mm}$ ou $1200 \mathrm{~mm}$. Nesse caso, se fossem observadas as orientações do Guia proposto, o engenheiro de produto poderia verificar a possibilidade de alterar a peça, na hora do projeto, para a largura de $333 \mathrm{~mm}$, já que o material é vendido em bobinas e blanques com largura de $1000 \mathrm{~mm}$. Caso isso não afetasse a qualidade do produto, esta alteração melhoraria significativamente o percentual de aproveitamento da peça. Vale lembrar que nem sempre é possível alterar as peças. Há casos em que até $1 \mathrm{~mm}$ faz diferença para a qualidade do produto, mas na maioria dos casos pequenas alterações podem ser feitas ou pelo menos podem ser analisadas sua viabilidade.

Quanto a falta de peças pequenas para programar os lotes, sugere-se que ao fazer os estoques de peças de maior saída dê-se preferência aquelas que não são utilizadas para aproveitamento nos lotes, ou que se for inevitável, que se faça um estoque de menor quantidade destas peças. Algumas delas são sabidamente usadas para melhorar o rendimento das chapas, ao fazer estoques destas peças se interrompe a geração de ordens de fabricação e consequentemente se aumenta o desperdício de material.

Um dos aspectos que mais afeta o aproveitamento das chapas são as restrições impostas pelas dimensões padrão dos blanques em estoque. Não há o que fazer em relação aqueles tipos de chapas que são vendidos apenas desta forma, porém aqueles blanques resultantes do final das bobinas quando não se consegue mais enrolá-las pode ser aperfeiçoado. $O$ que se sugere é que se faça um levantamento das peças de maior saída de cada tipo de chapa e, a partir destas informações, se desenvolva uma tabela com as dimensões de blanques próximos aos dessas peças. Assim, quando o programador CNC fosse programar essas peças ele poderia usar os blanques com as dimensões aproximadas. Por exemplo, umas das peças de maior saída da chapa $1,20 \mathrm{~mm}$ de espessura tem dimensões de $1800 \mathrm{~mm}$ x $995 \mathrm{~mm}$. Para este caso, quando o operador de desbobinadeira, ao constatar que não conseguirá mais enrolar uma bobina de chapa $1,20 \mathrm{~mm}$ poderia então, blanquear as chapas em $1820 \mathrm{~mm} \times 1000 \mathrm{~mm}$ por exemplo, consequentemente os programadores CNC teriam mais facilidade de utilizar esse blanque devido a peça apresentar um consumo significativo.

As questões referentes a características dos materiais, também são bem complexas. O setor de suprimentos da empresa, em muitos casos, necessita comprar os blanques de chapas ou as bobinas, em alguns casos, com até 3 meses de antecedência, por exigência dos fornecedores. Para isto, faz-se necessário levar em conta a capacidade dos estoques e possíveis perdas por oxidação e exposição ao ambiente. Por esses fatores pode-se dizer que as dificuldades encontradas pelos programadores no que diz respeito às dimensões dos materiais disponíveis, são questões realmente difíceis de serem resolvidas. No que diz respeito à qualidade do material, o setor de Qualidade, sempre que possível, realiza teste e quando este se encontra fora de especificações é devolvido o material ao fabricante, porém nem sempre o fornecedor aceita a devolução, e os programadores tem de utilizar o material defeituoso da melhor forma possível, mas como dito anteriormente nesses casos o fornecedor possui muita força.

Talvez o único ponto relativo a matéria-prima que caiba uma proposta seja quanto a falta de padronização de alguns materiais. Existem alguns tipos de chapas que possuem poucas peças ou peças de pouca saída, poderia ser feita uma revisão destes itens para se ter uma melhor noção de sua real necessidade e então reavaliar sua compra.

Quanto a quantidade de ordens o que é feito na empresa são os estoques de peças de maior saída, esses estoques geralmente são feitos nos meses de baixa, para amenizar os efeitos da sazonalidade do mercado de armazenagem de grãos, mas mesmo assim é inevitável que se tenha menos peças para produzir no primeiro semestre do ano. Cabe aos programadores CNC conviverem com esse empecilho.

As questões de segurança também acabam afetando os índices de desperdício, isso é mais visível nas Guilhotinas, onde o operador está mais exposto a riscos, por suas mãos ficarem próximas a 
navalha de corte. O programador CNC de Guilhotina leva esse fator em conta na hora de fazer os lotes da máquina deixando margens de segurança ao final das chapas quando necessário, porém isso é feito baseado na sua experiência, não há uma distância mínima estabelecida para estas margens, o que ocasiona desperdício quando é deixado uma margem maior do que a necessária e risco de acidente para o operador quando é deixada uma margem menor. O que se propõem nesse caso é que o setor de Métodos e Processos da empresa realize um estudo e estabeleça uma margem de segurança para cada máquina, com isso o operador CNC pode utilizar as chapas com a convicção de estar utilizando o máximo possível, e respeitando a segurança do operador.

As pressões vindas de outros setores da empresa por vezes acabam impondo que os programadores $\mathrm{CNC}$, façam os lotes com demasiada pressa, o que ocasiona pequenas perdas que somadas refletem diretamente no aproveitamento dos lotes. Se considerarmos que cada $\mathrm{Kg}$ desperdiçado representa cerca de R \$2,00, uma melhoria de $0,5 \%$ nos lotes de Guilhotina por exemplo representaria uma economia de mais de $\mathrm{R} \$ 81.000$ reais por ano, o que justificaria a contratação de mais funcionários para a função, que inclusive poderiam trabalhar em turnos opostos, utilizando os mesmos computadores e softwares.

No que diz respeito a capacidade de abrir ordens de fabricação ou aumentar a quantidade das peças das ordens já existentes, observou-se que os únicos funcionários que tem permissão para abertura ou alteração de ordens são os colaboradores da Programação da Produção - PCP. Por meio de relatórios, e consultas estes funcionários podem verificar as necessidades futuras, histórico de vendas e podem autorizar a abertura ou aumento da quantidade de peças de uma ordem para melhorar o aproveitamento das chapas. Eventualmente, a pedido dos programadores CNC, isso é feito, mas devido a distância física dos dois setores, e das outras atribuições do setor de PCP, essa sistemática é pouco utilizada. Diante deste fato, se propõem que haja uma maior interação entre esses dois setores, se possível que fiquem no mesmo ambiente, que se avalie a possibilidade de permitir a abertura de ordens por parte dos programadores $\mathrm{CNC}$, ou que seja criado outro canal ágil para a negociação deste tipo de decisão com o intuito de se maximizar a utilização das chapas de aço.

Outro ponto passível de melhora diz respeito a qualidade dos relatórios de aproveitamento dos lotes de fabricação. Em alguns casos faltam informações importantes como, por exemplo, o tipo de chapa a ser utilizada. Os relatórios, como são elaborados atualmente, informam apenas o aproveitamento dos lotes separando as chapas por espessura, agrupando assim vários tipos em um mesmo grupo. Considerando-se que a empresa trabalha com um número considerável de tipos de chapas esses relatórios limitam a capacidade assertiva de tomada de decisão em relação ao aproveitamento de materiais. Como exemplo, pode-se citar o caso da chapa 3,00mm de espessura que é encontrada em 10 características totalmente diferentes, mas os relatórios apresentam a soma dos aproveitamentos desses 10 tipos em um único grupo. Como esses dados são geradores de informação deveriam ser mais precisos. O que se propõem é que se desenvolva um relatório que possibilite também analisar as matérias-primas individualmente. Isso é importante para identificar possíveis níveis de desempenho abaixo do esperado e corrigi-los. 
Tabela 1 - Fator apurado x Melhoria proposta.

\begin{tabular}{|c|c|}
\hline Fator apurado & Melhoria proposta \\
\hline Dimensões das peças & $\begin{array}{l}\text { Criação de guia para utilização pela engenharia, este guia teria as } \\
\text { dimensões ideias de peças para cada tipo de chapa, para que } \\
\text { quando fosse possível as peças fossem projetadas com essas } \\
\text { medidas, ou aproximadas a elas. }\end{array}$ \\
\hline Pedidos urgentes & Fator de difícil solução, inerente ao processo. \\
\hline Poucas peças & Fator de difícil solução, inerente a sazonalidade do ramo. \\
\hline $\begin{array}{l}\text { Falta de padronização do } \\
\text { material }\end{array}$ & $\begin{array}{l}\text { Proposta de diminuição dos tipos de chapas por meio de análise } \\
\text { de sua real necessidade, visto que algumas possuem } \\
\text { caraterísticas parecidas. }\end{array}$ \\
\hline Largura do material disponível & $\begin{array}{l}\text { Fator de difícil solução, devido ao pequeno número de } \\
\text { fornecedores encontrados no mercado. }\end{array}$ \\
\hline Falta de peças pequenas & Fator de difícil solução, inerente ao processo \\
\hline Caraterísticas das máquinas & $\begin{array}{l}\text { Sugere-se que na compra de novas máquinas que se dê especial } \\
\text { atenção ao fator aproveitamento do material. }\end{array}$ \\
\hline Estoque de peças pequenas & $\begin{array}{l}\text { Sugere-se que ao fazer estoques de itens de maior saída que se } \\
\text { determine alguns itens que são sabidamente utilizados para } \\
\text { melhorar o aproveitamento das chapas, e não se faça estoque } \\
\text { desses itens. }\end{array}$ \\
\hline Qualidade do material & $\begin{array}{l}\text { Fator de difícil solução, devido ao pequeno número de } \\
\text { fornecedores encontrados no mercado. }\end{array}$ \\
\hline Blanques de chapa fina & $\begin{array}{l}\text { Criação de tabela para utilização na desbobinadeira, contendo as } \\
\text { dimensões das peças de maior saída de cada tipo de chapa, para } \\
\text { que se possa desbobinar blanques com dimensões próximas e } \\
\text { essas. }\end{array}$ \\
\hline Questões de segurança & $\begin{array}{l}\text { Definição por parte do MEP, de margens de segurança } \\
\text { específicas para cada máquina. }\end{array}$ \\
\hline Má identificação dos retalhos & $\begin{array}{l}\text { Uso de etiquetas de identificação geradas pelo software utilizado } \\
\text { pela empresa para simular os cortes das chapas. } \\
\text { Criação de central de retalhos. } \\
\text { Criação de cargo específico para coleta e identificação dos } \\
\text { retalhos. }\end{array}$ \\
\hline $\begin{array}{l}\text { Falta de informação sobre os } \\
\text { retalhos no sistema }\end{array}$ & $\begin{array}{l}\text { Criação de tela para consulta via sistema, contendo quantidade, } \\
\text { dimensões e tipo dos retalhos. }\end{array}$ \\
\hline $\begin{array}{l}\text { Tempo disponível para criação } \\
\text { dos lotes }\end{array}$ & $\begin{array}{l}\text { Sugere-se a contratação de novos programadores CNC, este } \\
\text { poderiam trabalhar em turnos opostos, utilizando os mesmo } \\
\text { computadores e softwares. }\end{array}$ \\
\hline
\end{tabular}

Fonte: Elaborada pelos autores.

\section{Considerações Finais}

Este trabalho teve por objetivo principal analisar os fatores que interferem no aproveitamento das chapas de aço em uma grande empresa do setor metal mecânico. Além dos objetivos estabelecidos, foi possível, durante o andamento do projeto adquiri novos aprendizados acerca das ações do PCP bem como o funcionamento operacional da fábrica, conhecimentos estes que, auxiliam para a formação e desenvolvimento da profissional na área de produção.

Durante a pesquisa foram identificados como fatores que interferem significativamente os seguintes pontos: dimensões variadas das peças; pedidos urgentes; variação no volume de peças a serem manufaturadas; falta de padronização do material; largura do material disponível; falta de peças pequenas para auxiliar na elaboração dos mapas de corte; caraterísticas das máquinas (bordas garras); estoque de peças pequenas; qualidade do material; blanques de chapa fina; questões de segurança no 
trabalho; má identificação dos retalhos; falta de informação sobre os retalhos no sistema e o tempo limitado para criação dos lotes de fabricação.

Dentre os fatores que acabam interferindo significativamente no aproveitamento das chapas de aço, pode ser destacada a quantidade de peças a serem cortadas, esse ponto tem uma relação direta com os níveis de desperdício, isso pode ser visto nos meses de baixa na empresa, no caso, o primeiro semestre. Outro ponto a se destacar diz respeito ao tratamento que a empresa dá aos retalhos, não existe uma política definida sobre o assunto e por muitas vezes chapas que poderiam ser utilizadas viram sucata metálica.

Durante a coleta dos dados pode-se observar como cada função e setores da organização possuem uma interdependência para que possam ser atingidos os resultados operacionais previstos. Isto pode ser observado nas consequências que trazem a realização de pedidos urgentes pela equipe de vendas ou pelas dimensões das peças projetadas pela engenharia de produto que limitam o aproveitamento de chapas no processo de corte e como ações desta natureza afetam o trabalho dos programadores $\mathrm{CNC}$ e na quantidade de chapas que são encaminhadas para a sucata pelo baixo aproveitamento do processo de corte.

O fator tempo também merece ser citado aqui como fator determinante no aproveitamento das chapas, visto que um maior tempo para realizar uma variedade de simulações resultaria em melhora do aproveitamento do corte, porém isso nem sempre é possível devido a pressões vindas de outras áreas da empresa com prazo exíguo de cumprimento.

Observou-se também que nem todos os fatores que interferem no aproveitamento das chapas de aço são de fácil solução e como os fornecedores podem afetar diretamente o produto e a eficácia dos processos da empresa, isso acontece devido as características dos materiais disponíveis a venda no mercado, e da pouca quantidade de oferta.

Dentre as propostas elaboradas a partir desta pesquisa e apresentadas em síntese no Quadro 1, podem ser destacadas algumas de soluções mais simples, cujo objetivo é o de auxiliar a empresa a melhorar seu aproveitamento de matéria-prima. Deve-se mencionar também que qualquer investimento utilizado para aperfeiçoar o processo de corte é justificável devido a grande quantidade de material processada, que consequentemente demanda um alto valor financeiro desperdiçado com geração de sucatas de chapas metálicas novas. Fatos como estes podem servir de fonte para novas pesquisas. Ao finalizar este trabalho, se ressalta a importância do trabalho das pessoas da área de PCP, das suas ações do dia-a-dia, do seu envolvimento com as diversas equipes da organização e da complexidade de suas atribuições.

Referências

BOYER, Kenneth; VERMA, Rohit. Operations \& supply chain management for the 21th century. Mason, USA: Cengage, 2010.

CAUCHICK, P. A. (org.) Metodologia de pesquisa em engenharia de produção e gestão de operações. Elsevier: Rio de Janeiro, 2012.

CORRÊA, C. A.; CORRÊA H. L.; Administração de Produção e Operações: Manufatura e serviços: Uma abordagem Estratégica. 2a ed. São Paulo: Atlas, 2006.

DUTRA, F.A.F.; ERDMANN, R. H. Análise do planejamento e controle da produção sob a ótica de teoria da complexidade. Produção, v.17, n.2, Mai-Ago, 2007.

FERNANDES, Laerte José; RODRIGUEZ, Luis Alberto Osés; CORREIA, Anderson Ribeiro e MARINS, Fernando Augusto Silva. Planejamento e controle da produção de cilindros para laminação: um estudo de caso quantitativo. Produção [online], vol.23, n.1, pp. 120-134, jan./mar. 2013. http://dx.doi.org/10.1590/S0103-65132012005000061

GIL, A. C. Como Elaborar Projetos de Pesquisa. São Paulo: Atlas, 2007. 
GAITHER, N.; FRAZIER, G. Administração da Produção e Operações. $8^{a}$ ed. São Paulo: Thomson, 2002.

HAIR, J. et al. Fundamentos de métodos de pesquisa em administração. Porto Alegre: Bookman, 2005.

HINCKELDEYN, Johannes; DEKKERS, Rob; KREUTZFELDT, Jochen. Productivity of product design and engineering processes: Unexplored territory for production management techniques? International Journal of Operations \& Production Management, vol. 35, n. 4, pp. 458-486, 2015.

LAKATOS, E. M.; MARCONI, M. A. Metodologia do Trabalho Científico: Procedimentos Básicos, Pesquisa Bibliográfica, Projeto e Relatório, Publicações e Trabalhos Científicos. $7^{\text {a }}$ ed. São Paulo: Atlas, 2007.

LAUGENI F. P.; MARTINS P. G. Administração da Produção. $2^{a}$ ed. São Paulo: Saraiva, 2006. LOULY, Mohamed-Aly; DOLGUI, Alexandre. Optimal time phasing and periodicity for MRP with $P O Q$ policy. International journal of production economics, v.131, n. 1, p. 76-86, 2011.

MAIA, Leonardo Caixeta de Castro. Contribuições para os estudos de estratégia de operações: um levantamento bibliográfico. Revista de Administração, Contabilidade e Economia da FUNDACE, v.3, n.1, 2012. DOI: http://dx.doi.org/10.13059/racef.v3i1.41

MARTINS, G. de A. Estudo de caso: uma estratégia de pesquisa. São Paulo: Atlas, 2006.

MORAES, R., GALIAZZI, M. C. Análise textual discursiva. Ijuí: Ed. Unijuí, 2007.

MOREIRA, D. A. Administração da Produção e Operações. $2^{a}$ ed. São Paulo: Cengage Learning, 2008.

RITZMAN, L. P.; KRAJEWSKI, L. J. Administração da Produção e Operações. São Paulo: Pearson, 2004.

RODRIGUES, D. S. S.; COSTA, H. G.; DO CARMO, L.F.R.R.S. Métodos de auxílio multicritério à decisão aplicados à problemas de PCP: mapeamento da produção em periódicos publicados no Brasil. Gestão \& Produção, v.20, n.1, 2013.

RUSSOMAnO, H. R. Planejamento e Controle da Produção. $5^{\text {a }}$ ed. São Paulo: Pioneira, 1995.

SLACK, N. et al. Administração da Produção: Edição Compacta. São Paulo: Atlas, 2007.

YIN, R. K. Estudo de caso: planejamento e método. 3. ed. Porto Alegre: Bookman, 2006.

VENANZI, D.; SILVA, O. R. Produção mais limpa: estudo sobre empresas fabricantes de componentes automotivos localizadas na cidade de Sorocaba - SP. GEPROS - Gestão da Produção, Operações e Sistemas, Ano 8, n. 1, Jan-Mar, 2013. 